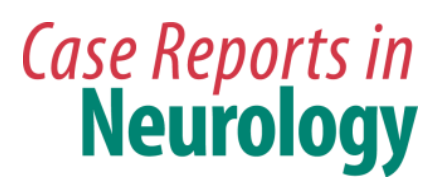

\title{
Dandy-Walker Malformation and Down Syndrome Association: Good Developmental Outcome and Successful Endoscopic Treatment of Hydrocephalus
}

\author{
Flavio Nigri Isaias Fiuza Cabral Raquel Tavares Boy da Silva \\ Heloisa Viscaíno Pereira Carlos Roberto Telles Ribeiro \\ Hospital Universitário Pedro Ernesto, Universidade do Estado do Rio de Janeiro, \\ Rio de Janeiro, Brazil
}

\section{Key Words}

Dandy-Walker malformation · Down syndrome $\cdot$ Prenatal diagnosis

\begin{abstract}
The association of Down syndrome (DS) with Dandy Walker malformation (DWM) is extremely rare, with only 3 cases reported to date. All cases reported have shown a bad life expectancy and a bad developmental outcome. The present case reveals the possibility of a good prognosis. A 19-month-old male patient had successful endoscopic hydrocephalus treatment and a good developmental outcome. He probably had a better outcome because of good DS and DWM prognostic parameters. Our patient suffered from a DWM with vermis identification of 2 fissures and 3 lobes and a DS with a well-preserved tonus, which was not associated with other congenital systemic defects. We may conclude that the prognosis of DS-DWM association may separately depend on the degree of clinical and neurological involvement of each malformation.

(c) 2014 S. Karger AG, Basel
\end{abstract}

\section{Introduction}

Down syndrome is the most common genetic cause of mental retardation [1]. Its association with Dandy-Walker malformation is extremely rare, with only 3 cases reported to date 
Nigri et al.: Dandy-Walker Malformation and Down Syndrome Association: Good Developmental Outcome and Successful Endoscopic Treatment of Hydrocephalus

[2-4]. All cases reported have shown a bad life expectancy and/or a bad developmental outcome. The present case reveals the possibility of a good prognosis.

\section{Case Report}

A 19-month-old male patient was referred to our neurosurgical unit because of hydrocephalus that caused progressive macrocrania. He was diagnosed with a prenatal ultrasonographic diagnosis of Dandy-Walker malformation (DWM) and a trisomy 21 karyotype. The neurological examination revealed a child with irritability, a cephalic perimeter of $53 \mathrm{~cm}$ and a bulging fontanel. He was active and reactive, mildly hypotonic, but still unable to walk independently or verbalize himself. His CT scan showed tetraventricular hydrocephalus, a posterior fossa cyst and an effacement of his cortical sulcus (fig. 1a, b). His MRI revealed a fourth ventricle dilatation, a hypoplastic cerebellar vermis with an upward displacement and an open aqueduct of Sylvius (fig. 2a). Third ventricle floor and lamina terminalis bulging on his MRI 3D-continuous-flow isotonic solution system sequence suggested the obstructive pattern of the hydrocephalus (fig. 2a), and an endoscopic third ventriculostomy (ETV) was performed. He had an uneventful postoperative outcome and was discharged on the third day. A 99mTc-DTPA ventriculocisternography [5] (injection of the radioisotope inside the lateral ventricle) performed after the ETV revealed a normal cerebrospinal circulation and absorption. A CT scan performed 7 months post-op showed a decreased ventricle size and a reappearance of the cortical sulcus (fig. 1c, d). An 18-month post-op MRI revealed the absence of the third ventricle floor and the lamina terminalis bulging, and the flow void changes in the floor of the third ventricle confirmed an ETV patency (fig. 2b, c). A systematic developmental exam based on the Denver II developmental scale [6] and a full neurological exam was performed at the age of 4 years and 10 months. Gross motor skills, fine motor skills, language and social domains were evaluated. His gross motor skills compared to when he was 3 years and 3 months old, his fine motor skills compared to when he was 3 years and 9 months old, his language was compared to when he was 3 years and 6 months old, and his social skills were those of a 3-year-old. The main qualitative difficulties in acquiring a fine motor performance was related to his deficits in coordination, which restrained the boy from activities such as brushing his teeth and getting dressed. The neurological examination revealed a slightly dysmetric motor pattern with bilateral and symmetrical intentional tremor. The parents referred to this as having only a small impact in their daily life activities. A unilateral right Babinski sign with no other showings of pyramidal dysfunction was verified. Cooperation and behavior were adequate. His tonus was well preserved, with a slightly decreased resistance to passive movement and relative joint hyperextensibility. The boy's posture and strength were comparable with the expected developmental stage of Down syndrome (DS) patients at the same age. His gross motor function measure raw score was $96.1 \%$ and therefore compatible with the expected DS population score [7]. The cephalic perimeter was $55.5 \mathrm{~cm}$.

\section{Discussion}

A retrospective study with a prenatal diagnosis of the fetal posterior fossa fluid showed that isolated DWM and vermian hypoplasia were associated with the normal developmental outcome in only $50 \%$ of cases [8]. A potentially good clinical and intellectual outcome has been demonstrated to occur in fetuses showing partial vermian agenesis, i.e., with the 
identification of 2 fissures and 3 lobes and with an absence of associated intracranial and extracranial anomalies $[9,10]$. ETV is considered to be an acceptable alternative for DWM hydrocephalus treatment, especially in older children, with the aim of reducing the shuntrelated problems [11]. Cases with third ventricular bowing increase the ETV success rate [12]. DS developmental outcome is characterized by a weakness in communication, combined with daily living and social skills [13]. Delays in motor development of patients with DS appear to be particularly related to the degree of hypotony [14]. The combination of DS and DWN is a bad prognosis for affected subjects. The first patient died at the age of 2 weeks [3] and the second was severely handicapped at the age of 4 months [4]; the third patient, a 37-month-old male, was unable to crawl or ambulate independently [2]. The present case however had a better outcome, probably because of good prognostic parameters. Our patient suffers from DWM with a vermis identification of 2 fissures and 3 lobes (fig. 2c) and no associated intracranial or extracranial anomalies. Although a dysmetric motor profile was constructed, a possible consequence of the cerebellar malformation has a small impact in his daily life activities. His DS was not associated with any other congenital systemic defects and presents a well-preserved tonus and gross motor function scores comparable to isolated DS patients.

\section{Conclusion}

We conclude that the prognosis of the DS-DWM association may separately depend on the degree of clinical and neurological involvement of each malformation.

\section{Disclosure Statement}

The authors have no personal financial or institutional interest in any of the drugs, materials or devices mentioned in the article.

\section{References}

1 Canfield MA, Honein MA, Yuskiv N, Xing J, Mai CT, Collins JS, Devine O, Petrini J, Ramadhani TA, Hobbs CA, Kirby RS: National estimates and race/ethnic-specific variation of selected birth defects in the United States, 1999-2001. Birth Defects Res A Clin Mol Teratol 2006;76:747-756.

-2 Love K, Huddleston L, Olney P, Wrubel D, Visootsak J: Developmental outcomes of Down syndrome and Dandy-Walker malformation. J Pediatr Neurol 2011;9:405-408.

-3 Constantini S, Pomeranz S, Hoffman B, Martin O, Rappaport ZH: Coexistence of Dandy-Walker syndrome and Down's syndrome. Neurochirurgia (Stuttg) 1989;32:56-57.

$\checkmark 4$ Estroff JA, Scott MR, Benacerraf BR: Dandy-Walker variant: prenatal sonographic features and clinical outcome. Radiology 1992;185:755-758.

5 Nigri F, Bernardo-Filho M, Telles C, Silva JW, Boasquevisque EM: 99mTc-DTPA ventriculocisternography for postoperative evaluation of endoscopic third ventriculostomy: a preliminary study model. Biomed Research 2004;15:138-141.

-6 Frankenburg WK, Dodds J, Archer P, Shapiro H, Bresnick B: The DENVER II: A major revision and restandardization of the Denver Developmental Screening Test. Pediatrics 1992;89:91-97.

-7 Palisano RJ, Walter SD, Russell DJ, Rosenbaum PL, Gemus M, Galuppi BE, Cunningham L: Gross motor function of children with Down syndrome: creation of motor growth curves. Arch Phys Med Rehabil 2001;82:494-500.

8 Gandolfi Colleoni G, Contro E, Carletti A, Ghi T, Campobasso G, Rembouskos G, Volpe G, Pilu G, Volpe P: Prenatal diagnosis and outcome of fetal posterior fossa fluid collections. Ultrasound Obstet Gynecol 2012;39:625-631. 


\begin{tabular}{l|l}
\hline Case Rep Neurol 2014;6:156-160 \\
\hline DOI: $10.1159 / 000363179$ & $\begin{array}{l}\text { C 2014 S. Karger AG, Basel } \\
\text { www.karger.com/crn }\end{array}$ \\
\hline
\end{tabular}

Nigri et al.: Dandy-Walker Malformation and Down Syndrome Association: Good Developmental Outcome and Successful Endoscopic Treatment of Hydrocephalus

-9 Klein O, Pierre-Kahn A, Boddaert N, Parisot D, Brunelle F: Dandy-Walker malformation: prenatal diagnosis and prognosis. Childs Nerv Syst 2003;19:484-489.

10 Patek KJ, Kline-Fath BM, Hopkin RJ, Pilipenko VV, Crombleholme TM, Spaeth CG: Posterior fossa anomalies diagnosed with fetal MRI: associated anomalies and neurodevelopmental outcomes. Prenat Diagn 2012;32:75-82.

11 Spennato P, Mirone G, Nastro A, Buonocore MC, Ruggiero C, Trischitta V, Aliberti F, Cinalli G: Hydrocephalus in Dandy-Walker malformation. Childs Nerv Syst 2011;27:1665-1681.

$\$ 12$ Dlouhy BJ, Capuano AW, Madhavan K, Torner JC, Greenlee JD: Preoperative third ventricular bowing as a predictor of endoscopic third ventriculostomy success. J Neurosurg Pediatr 2012;9:182-190.

$\checkmark 13$ Dykens EM, Hodapp RM, Evans DW: Profiles and development of adaptive behavior in children with Down syndrome. Downs Syndr Res Pract 2006;9:45-50.

14 Weijerman ME, de Winter JP: The care of children with Down syndrome. Eur J Pediatr 2010;169:14451452.

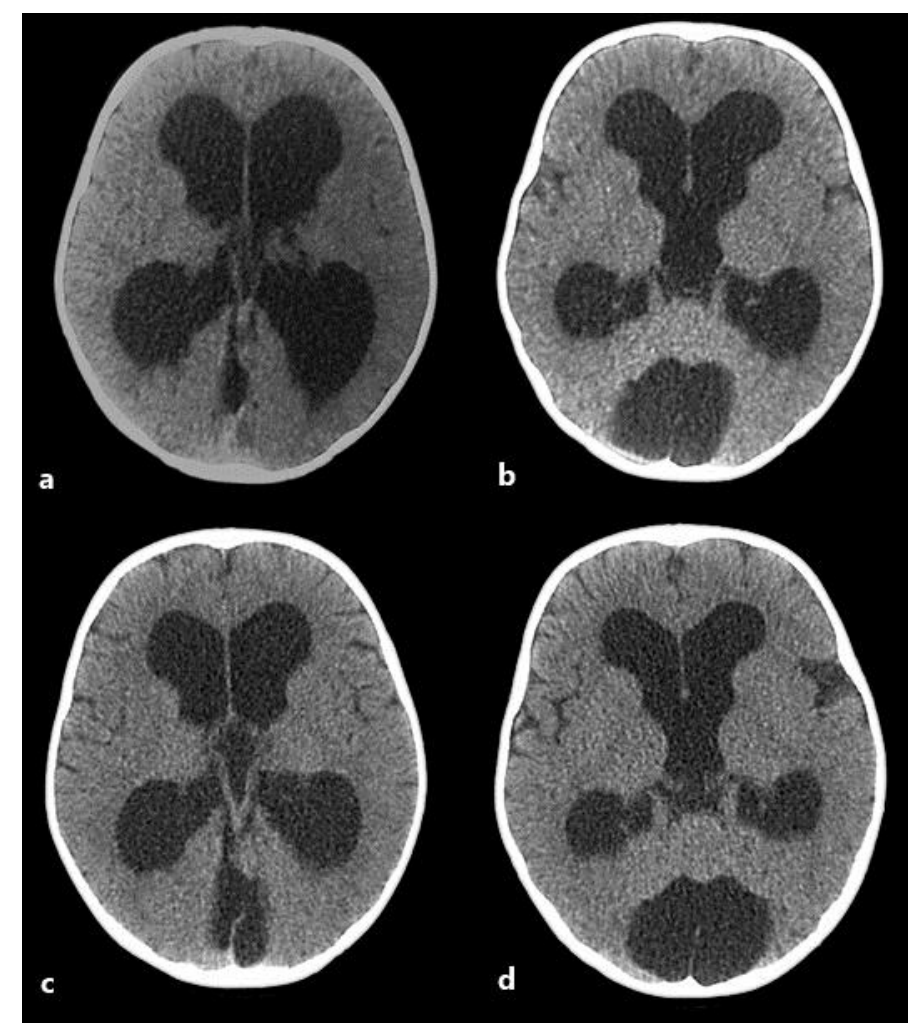

Fig. 1. a, b Preoperative CT scan showing the tetraventricular hydrocephalus, posterior fossa cyst and the effacement of cortical sulci. c, d Postoperative CT scan showing a decreased ventricle size and a reappearance of cortical sulci. 


\section{Case Reports in Neurology}

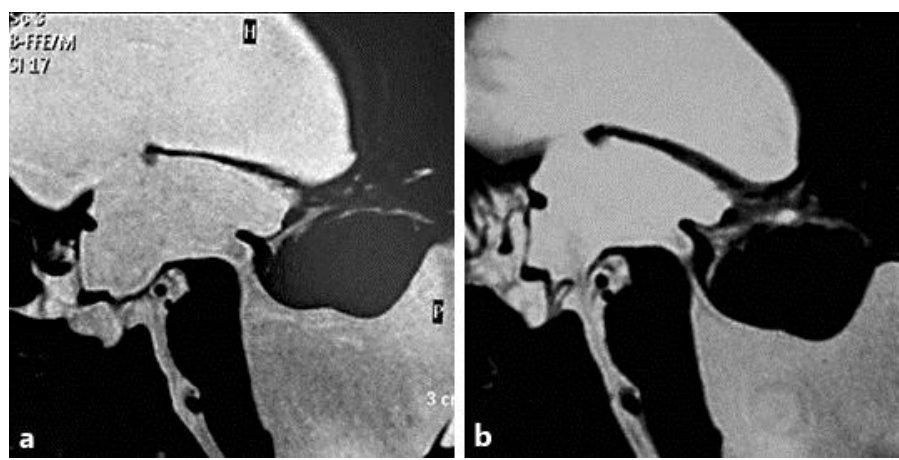

Nigri et al.: Dandy-Walker Malformation and Down Syndrome Association: Good Developmental Outcome and Successful Endoscopic Treatment of Hydrocephalus

Fig. 2. a Preoperative MRI on 3D-continuous-flow isotonic solution system sequence showing the posterior fossa cyst, cerebellar vermis hypoplasia, open aqueduct, the third ventricle floor and the lamina terminalis bulging. b Postoperative MRI on 3D-continuous-flow isotonic solution system sequence with the reversion of the third ventricle floor and the lamina terminalis bulging. c Postoperative MRI T2weighted sequence showing the flow void signal on the third ventricle floor and the cerebellar vermis hypoplasia with the identification of 2 fissures and 3 lobes. 